\title{
MULTI-DETECTOR COMPUTED TOMOGRAPHY IN ABDOMINAL TUBERCULOSIS
}

Omprakash A. R¹, Reshmina C. D’Souza ${ }^{2}$, Sunil H. Sudarshan³, Vishwanath Yadav,P.S. Aithala5, Ramakrishna Pai J ${ }^{6}$, Aaron Marion Fernandes ${ }^{7}$, Tessa Jose Kaneria ${ }^{8}$,

\section{HOW TO CITE THIS ARTICLE:}

Omprakash A.R, Reshmina C. D'Souza, Sunil H. Sudarshan, Vishwanath Yadav, P.S. Aithala, Ramakrishna Pai J, Aaron Marion Fernandes, Tessa Jose Kaneria. "Multi-Detector Computed Tomography in Abdominal Tuberculosis". Journal of Evolution of Medical and Dental Sciences 2014; Vol. 3, Issue 03, January 20; Page: 565-568, DOI:10.14260/jemds/2014/1866

ABSTRACT: BACKGROUND: In a country like India where tuberculosis is rampant and considered as a major public health problem so much that there are national programs aimed towards this disease. Pulmonary form is the most common form but extra- pulmonary form of the disease is accounts for $57.9 \%$ of all cases of tuberculosis, in which abdominal TB accounts for most cases. The diagnosis of extra-pulmonary tuberculosis is often difficult because of its varied clinical manifestations .In the abdomen the disease can affect intestinal tract, lymph nodes, peritoneum and solid viscera. CT provides a comprehensive overview of all the abdominal structures and is the imaging modality of choice for evaluation of such patients. In view of this we studied the role of multi-detector computed tomography in diagnosing abdominal tuberculosis. AIMS: The role of multi-detector computed tomography in diagnosing abdominal tuberculosis. METHODS AND MATERIALS: This was a study done between over a period of from between December 2011 to November 2012. The reports of all patients who were referred for abdominal CT were searched for tuberculosis and the data was co-related as to whether the patients had tuberculosis. RESULTS: During this period of study a total of 212 studied, 5 cases were diagnosed as having tuberculosis based on abdominal CT. Ascites which was not attributable to any specific disease as a feature; peritoneal involvement was another common feature. CONCLUSION: Tuberculosis continues to be endemic in the developing world and diagnosis of abdominal tuberculosis is usually very difficult, due to nonspecific symptoms and signs. The developments in imaging modalities like CT help in identifying cases of abdominal tuberculosis and the overall organ involvement and should be used whenever there is a high index of clinical suspicion is high.

KEY WORDS: MDCT; multi-detector computed tomography, abdominal tuberculosis

INTRODUCTION: In a country like India where tuberculosis is rampant and considered as a major public health problem so much that there are National Programmers' aimed towards this disease. In extra- pulmonary form of the disease abdominal TB accounts for most cases. The diagnosis of extrapulmonary tuberculosis is often difficult because of its varied clinical manifestations .In the abdomen the disease can affect intestinal tract, lymph nodes, peritoneum and solid viscera. CT provides a comprehensive overview of all the abdominal structures and is the imaging modality of choice for evaluation of such patients. In view of this we studied the role of multi-detector computed tomography in diagnosing abdominal tuberculosis

METHODS AND METHODS: This was a study done between over a period from between July 2011 to November 2012 on patients who were referred to the department of Radio-diagnosis for 
abdominal CT and their imaging features suggested tuberculosis. The reports of all patients who were referred for abdominal CT were searched for tuberculosis and the data was co-related as to whether the patients had tuberculosis.

RESULTS: During this period of study a total of 282 cases were referred for abdominal CT of which 84 scans were for abdominal trauma. Among the rest 136, 23cases were normal.186 cases had findings not related tuberculosis which included findings like liver metastasis, intestinal obstructions, and malignancies of various organs. 8 cases were diagnosed as having tuberculosis based on abdominal CT, and 1 had renal tuberculosis.

\begin{tabular}{|c|c|}
\hline No of findings & 8 \\
\hline Single finding & 1 \\
\hline Multiple finding & , \\
\hline
\end{tabular}

\begin{tabular}{|c|c|}
\hline Multiple finding & 7 \\
\hline Bowel, lymph node, Ascites & 4 \\
\hline lymph node, Ascites & 2 \\
\hline Solid organ involvement, Ascites & 1 \\
\hline
\end{tabular}

Table 2:-Division of the multiple findings

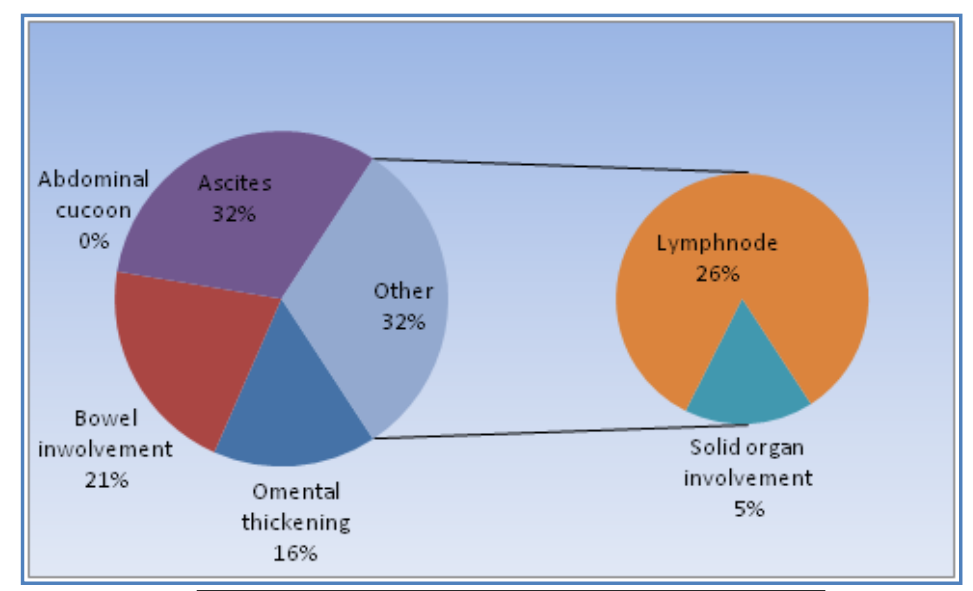

Table/figure 3:-Type of findings

DISCUSSION: India is an endemic country for tuberculosis ${ }^{1}$. With the increase in immune compromising diseases like AIDS there has been a global resurgence of tuberculosis ${ }^{2}$. As early as fourth century B.C the disease was recognized known with different names like the phthisis, lupus, scrofula or Pott's disease until in the late eighteenth century A.D when all these diseases were brought under one roof by Robert Koch who discovered this bacillus which bears his name ${ }^{3}$. Extra pulmonary tuberculosis can affect any and every system in the body. A high index of clinical suspicion is needed as the presentation of extra pulmonary forms of TB abdominal is diverse. In surgical practice the extra-pulmonary forms are most commonly encountered in contrast to the pulmonary form of tuberculosis which is dealt by the physicians. Extrapulmonary tuberculosis constitutes $57.9 \%$ of all cases of tuberculosis 5 . Abdominal tuberculosis is the sixth most common extra pulmonary form and accounts for $10-12 \%$ of all extra pulmonary forms tuberculosis ${ }^{6-9}$ the importance of this disease is well understood by the fact that in 1993 WHO declared this disease as a 
global health emergency ${ }^{10,11}$. Intestinal variety of tuberculosis is the most common form of tuberculosis in the abdomen 12 .

The making of a diagnosis in the present practice of medicine is helped by many investigations; imaging is one such technology. Medical imaging has come a long way from the Xrays to the modern scanners. The development in the fields of radio-diagnosis have helped the clinicians in recognition of abdominal tuberculosis at early stages when the disease is amenable to medical therapy and the morbidity associated with surgery avoided. CT has proved useful in making the diagnosis of intestinal tuberculosis especially when the inflammatory process is mild. It also points the location of lesion which helps to clinch the diagnosis of tuberculosis in the abdomen. There are variable imaging features of abdominal tuberculosis which are better demonstrated on MDCT.

Although no single feature is diagnostic, a combination of imaging features when correlated with clinical and imaging data can help in clinching the diagnosis. Epstein ${ }^{13}$ in his study of abdominal tuberculosis showed that presence of irregular soft-tissue densities in the omental area; low-density masses surrounded by thick solid rims; a disorganized appearance of soft-tissue densities, fluid, and bowel loops forming a disorganized appearance of soft-tissue densities, fluid, and bowel loops forming a poorly defined mass; low-density lymph nodes with a multilocular appearance after intravenous contrast administration; and possibly high-density ascites suggest highly the presence of abdominal tuberculosis. Similar findings were earlier reported by Suri14, and his colleagues. In another study they showed that peritoneal involvement was the most common feature and ascites was seen in most cases ${ }^{15}$.

CONCLUSION: Tuberculosis continues to be endemic in the developing world and diagnosis of abdominal tuberculosis is usually very difficult, due to nonspecific symptoms and signs. The developments in imaging modalities like CT help in identifying cases of abdominal tuberculosis and the overall organ involvement and should be used whenever there is a high index of clinical suspicion is high.

\section{ACKNOWLEDGMENTS:}

1. To all the unit heads of the surgical units for supporting in conducting the study

2. To the administration of the institution for allowing to conduct the study

3. To the anaesthesia and general surgical residents for their prompt services whenever required

4. To the department of radiologyfor their prompt services whenever required

\section{REFERENCES:}

1. World Health Organization (2009). "Epidemiology". Global tuberculosis control: epidemiology, strategy, financing. pp. 6-33. ISBN 978-92-4-156380-2. Retrieved 12 November 2009.

2. J.R Glyn: Resurgence of tuberculosis and the impact of HIV: British Medical Bulletin: 1998, 54((3) 579-593.

3. Uzunkoy A, Harma M, Harma M.Diagnosis of abdominal tuberculosis: Experience from 11 cases and review of the literature.World Journal of Gastroenterology 2004; 10(24):3647-3549.

4. Carter KC, editor. Essays of Robert Koch: Contributions in Medical Studies. Westport: Greenwood Press; 1987. pp. ix-xxv. 
5. Faten Tinsa, Leila Essaddam, Zohra Fitouri, Faouzi Nouira, Wiem Douira, Saida Ben Becher, Khadija Boussetta, Souad Bousnina :Extra-Pulmonary Tuberculosis In Children: A Study Of 41 CasesLa tunisie Medicale - 2009 ; Vol 87 ( n010) : 693 - 698.

6. Sochocky S. Tuberculous peritonitis. A review of 100 cases. Am Rev Respir Dis 1967; 95: 398-40.

7. Marshall JB. Tuberculosis of the gastrointestinal tract and peritoneum. Am J Gastroenterol. 1993;88:989-99.

8. Aston NO. Abdominal tuberculosis. World J Surg. 1997;21:492-9.

9. Kapoor VK. Abdominal tuberculosis: The Indian contribution. Indian J Gastroenterol. 1998;17:141-7.

10. "Frequently asked questions about TB and HIV". World Health Organization. Retrieved 15 April 2012.

11. Bates JH, Stead WW:The history of tuberculosis as a global epidemic: Med Clin North Am. 1993 Nov;77(6):1205-17.

12. PF Schofield: Abdominal tuberculosis:Gut,1985,26,1275-127.

13. Epstein BM, Mann JH.:CT of abdominal tuberculosis. AJR Am J Roentgenol. 1982 Nov;139(5):8616.

14. S Suri, S Gupta, R Suri,: Pictorial review. Computed tomography in abdominal tuberculosis. Br J Radiol. 1999 Jan;72(853):92-8.

15. T Sinan, M Sheikh, S Ramadan, S Sahwney,Behbehani: CT features in abdominal tuberculosis: 20 years' experience.BMC Medical Imaging 2002, 2:3.

\section{AUTHORS:}

1. Omprakash A.R,

2. Reshmina C. D'Souza,

3. Sunil H. Sudarshan,

4. Vishwanath Yadav

5. P.S. Aithala

6. Ramakrishna Pai J

7. Aaron Marion Fernandes,

8. Tessa Jose Kaneria,

\section{PARTICULARS OF CONTRIBUTORS:}

1. Resident, Department of Radiology, Father Muller Medical College.

2. Assistant Professor, Department of General Surgery, Father Muller Medical College.

3. Junior Consultant, Department of General Surgery, St. Marthas, Bangalore.

4. Resident, Department of Radiology, Navodaya Medical College.

5. Professor \& HOD, Department of General Surgery, Shrinivas Medical College.
6. Assistant Professor, Department of Microbiology, Father Muller Medical College.

7. Resident, Department of General Surgery, Father Muller Medical College.

8. Senior Resident, Department of Radiology, Father Muller Medical College.

\section{NAME ADDRESS EMAIL ID OF THE CORRESPONDING AUTHOR:}

Dr.Reshmina C. D'Souza, Assistant Professor, Father Muller Medical College, Kankanady, Mangalore - 575002. Email-dsouzareshmina@gmail.com Spanspan77@gmail.com

Date of Submission: 26/12/2013. Date of Peer Review: 27/12/2013. Date of Acceptance: 07/01/2014. Date of Publishing: 14/01/2014 